\title{
Risk analysis and GIS application in territorial planning and emergency management
}

\author{
V. Bartolozzi, L. Marceca, S. Bajardi, F. Vasile \& S. Marino \\ Agenzia Regionale per la Protezione dell'Ambiente ARPA, Sicilia, Italy
}

\begin{abstract}
The work proposed is mainly based on the theme of relevant accident risk and in particular industrial risk management.

The work affords a critical and comparative analysis of the politics of relevant accident prevention and the safety management system of two different industrial installations, which differ both in their size and their productive qualities.

In this work we test the techniques for the identification of potential hazards, give an estimate of their possible consequences and compare some methods for the selection of safety measures.

The starting point is the application of the software ARIA 334 (Aziende a Rischio di Incidente rilevAnte) for GIS application in the Sicilian territory.

Information on hazards, together with environmental and demographic information, has been extracted from official safety reports.

The software must operate under the control of a visual interface for the graphical layout of the equipment and the interconnecting currents.

Considering the particular features of vulnerability of the Sicilian territory, the information obtained allows for the mapping of the risk giving a fundamental contribution to activities of territorial planning and for emergency management.
\end{abstract}

\section{Introduction}

Risk identification of a potentially dangerous installation plays a fundamental role in attaining the desired level of safety. This phase consists of identifying the possible significant incidents through applying systematic investigation techniques. 
Planning for emergencies whose consequences could have an impact on the population and the environment is an aspect of particular importance in the risk analysis in order to prepare adequate actions with the relevant authorities capable of managing them.

The main objective of emergency planning is to identify problems that could occur after the incident and to predispose the relevant resources and procedures to protect the population, the workers and the environment.

Many research groups are interested in the solutions to various problems inherent in safety analysis: these activities mainly regard the use of software for the calculation of the consequences of possible incidents and the development of support systems destined for planning and managing such emergencies.

Project HARIA-2 [1] defines an easy methodology for analyzing and managing emergencies in chemical and petrolchemical installations, using different models and databases.

For the area risk assessment a new code of risk calculation has been applied. VARIAR [2] developed from the APAT (Agenzia Nazionale per la Protezione dell'Ambiente e i Servizi Tecnici) that considers the risk associated with industrial installations and transport.

Bartolozzi et al. [3] addressed the issue of automating the HAZOP analysis for continuous, semi continuous and batch chemical plants, starting from the support system for hazard analysis STARS (Software Tool for Analysis of Reliability \& Safety) [4] modified in order to include a new module, HAST (HAZOP Support Tool) [5]).

Carcassi et al. [6], applied a software MARA-ROAD (Manual of Risk Analysis - Road) in a case-study relative to the industrialized area of Piombino (Italy) in which the impact of the transport of dangerous substancies has been analyzed.

The APAT (Agenzia Nazionale per la protezione dell'Ambiente e i Servizi Tecnici) according to D.Lgs. 334/99, implementation of directive 96/82/CE, collaborates with the Italian Ministry for the Environment to predispose the national inventory of the industrial activities and the database of final results of SMS (Safety Management Systems) auditing and safety reports examination.

For these reasons, in 1998 the APAT carried out several studies for the production of a GIS informative system dedicated to represent the national industrial area. The pilot plan started in collaboration with ARPA (Agenzia Regionale per la Protezione dell'Ambiente) of the Veneto, to analyze the industrial area of Porto Marghera (VE).

With the ARPA Toscana collaboration, an integrated technical GIS support has been implemented to extend the study to national territory, in particular:

- control of industrial installation;

- $\quad$ planning and management of the territory;

- $\quad$ planning and management of the external emergencies.

The GIS system allows the information regarding the industrial installation to be used with an alphanumerical database, the principal sections of which are: 
1. general information

2. administrative condition

3. territorial information

4. environmental information

5. identification of dangerous substances
6. equipment units of plant

7. parameters for indication of the critical areas

8. prevention and protection measures

9. risk analysis

The program has been implemented in two independent parts: an alphanumeric part with the administrative and technique information extracted from safety reports, in which events, substances and scenes can be related. Using the functionalities base of the software Arc VIEW GIS, the GIS part contain the information about plants, equipment units, vulnerable areas, etc.). Distribution concerning the population and public areas such as schools, hospitals, museums, etc. that are available in the data base have been extracted from the external emergency plans.

\section{Operating management of the emergency}

The principal concepts on which the territorial planning is based can be reported as follows:

- risk definition;

- identification and analysis of territorial risk;

- definition methodologies of quantification of the risk;

- definition of the tolerance criterion of the risk;

- indication of the prevention and protection means for the reduction of the risk;

- information, formation and training activity;

- indications about organizational measures to activate the emergency.

Art. 14 of D. Lgs 334-1999 states that the Italian minister for public works, the Italian minister for the interior, the Italian minister for the environment and the Italian minister of industry, together with the State-Regions Conference, must establish detailed emergency territorial planning for zones deemed to be at a high risk, with the objective of preventing incidents and reducing consequences.

The individual regions must locate the industrial areas and predispose regional general plans. The Mayors have the task of coordinating the regulator plans for an environmental emergency and can impose appropriate provisions for residential zones to be protected.

\section{Case studies}

\subsection{Methodology application in LPG industrial installation}

The studied industrial installation is located in an industrial area about $20 \mathrm{~km}$ away from a residential zone. The industrial activity consists of storing LPG, 
blending, filling of gas and liquid hydrocarbons and their mixtures. This industrial installation is subject to the normal risks of relevant accidents (art. 8 D. Lgs 334/99) because of the detention of the LPG product, which is extremely flammable.

The industrial plant has a total capacity of $200 \mathrm{t}$ as cylinders and vessels. The fixed storage consists of four vessels located above ground, which are cylindrical with a horizontal axis and hemispheric heads. The vessels are totally covered and the covering material is supported by a reinforced concrete wall.

The vessels are equipped with a single connection on the bottom, which is used for aspiration and only certified safety valves are used. Eventual releases are intercepted on the process piping, with manual or pneumatic control valves.

All valves will be automatically closed when the presence of gas LPG is detected in the atmosphere and in the case of a rise in temperature. Additional manual safety instrumentation such as emergency push-buttons, has been located in several zones of the plant. Obviously the closing of the valves will always determine the immediate stop of the pumps and compressors.

Several gas detectors has been installed in particular hazardous points of the industrial installation such as the storage area, the filling area, the pumps and compressors room, refuelling points, warehouse cylinders, and are connected with the control room. Both the filling area and the temporary storage zone of full cylinders are protected with a water sprinkler system. The safety report of the company examines the units housing the technical equipment at the plant, highlighting the operating procedures of production processes, the detection quantity of LPG both in normal process conditions and in anomalous conditions associated with an emergency.

Besides the complete hazard analysis, five critical areas have been located:

- storage area of LPG in vessels

- refuelling area of LPG

- pumping and compression area

- filling and temporary warehouse cylinder area

- piping and connections.

The risk analysis shows that serious incidents for the population and environment could start as a result of the release of flammable products from piping, flanges and valves (39\%), operative errors (35\%), and transport incidents $(13 \%)$.

In this study, the causes of possible events have been evaluated together with the effects, the reaction times, and the consequences on the territory and the environment. The considered events are the jet fire that involves the filling shed, and a flash fire from the refuelling point.

The product boiling point and flammability temperature of butane and propane are such that, in a case of liquid release of LPG, a part vaporizes instantaneously and it will form gas cloud with concentrations comprised within the flammability limits. The LPG vapours have a high relative density $(1,5-2,0)$, so in the low zones are very concentrated. 
The analyses have been carried out considering the propane release at rotating filling machines, considering also the time taken to detect the hazard and the time when blocks and safety equipment units start.

The frequency calculated through the method of fault tree, making use of literature data and considering the characteristics of the plant, is $1 \times 10^{-3}$ occ/years. It assumes that the complete piping burst occurs, and the rate of release is $15 \mathrm{~kg} / \mathrm{s}$ per 30 seconds.

Assuming that a source of ignition is present (naked flames, sparks, electrical or electrostatic discharges) and the release evolves in the jet fire, the incident consequences produce radiation $\left(12,5 \mathrm{kw} / \mathrm{m}^{2}-65 \mathrm{~m}, 7 \mathrm{kw} / \mathrm{m}^{2}-72 \mathrm{~m}\right.$, and 5 $\left.\mathrm{kw} / \mathrm{m}^{2}-81 \mathrm{~m}\right)$.

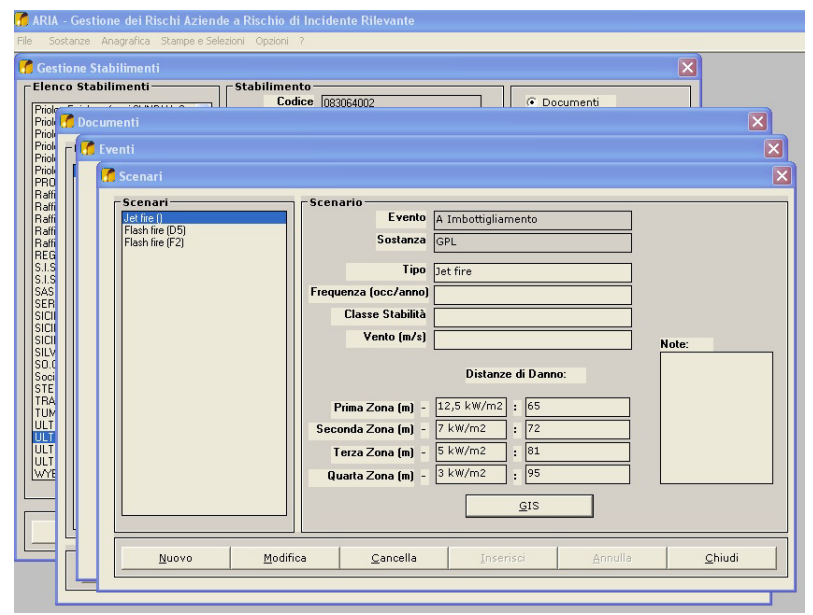

Figure 1: $\quad$ ARIA 334 - Scenario data.

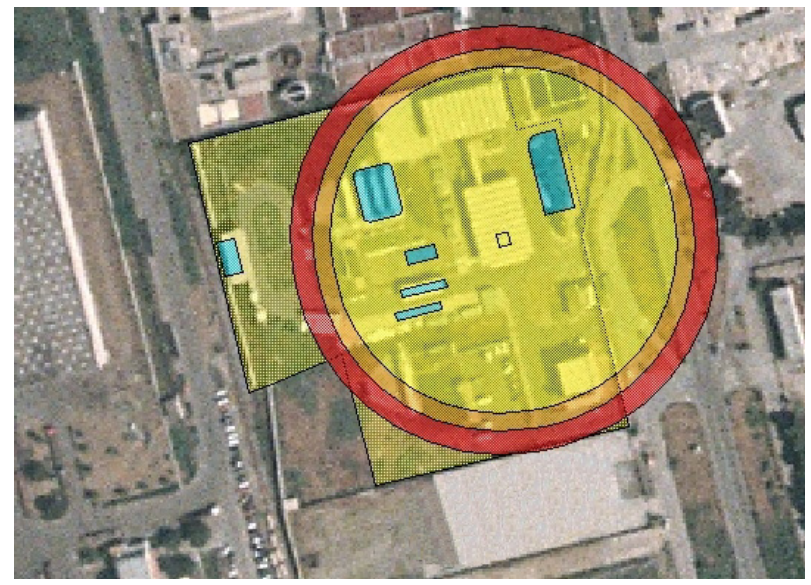

Figure 2: ARIA 334 - Jet-fire scenario representation. 
The effects of jet fire could involve other units; however the eventual collapse of the piping could not cause a worsening of the emergency situation, because the piping could be completely intercepted.

The last event is a flash fire at the refuelling area. The accident is a result of the ignition of a release of LPG after a total burst (100\%) of feeding (2"), and correspondent release of $20,8 \mathrm{~kg} / \mathrm{s}, 180$ second ones.

The damage distances have been calculated on the basis of the atmospheric flammable gas concentration (LFL to $79 \mathrm{~m}$ and $1 / 2$ LFL to $85 \mathrm{~m}$ ).

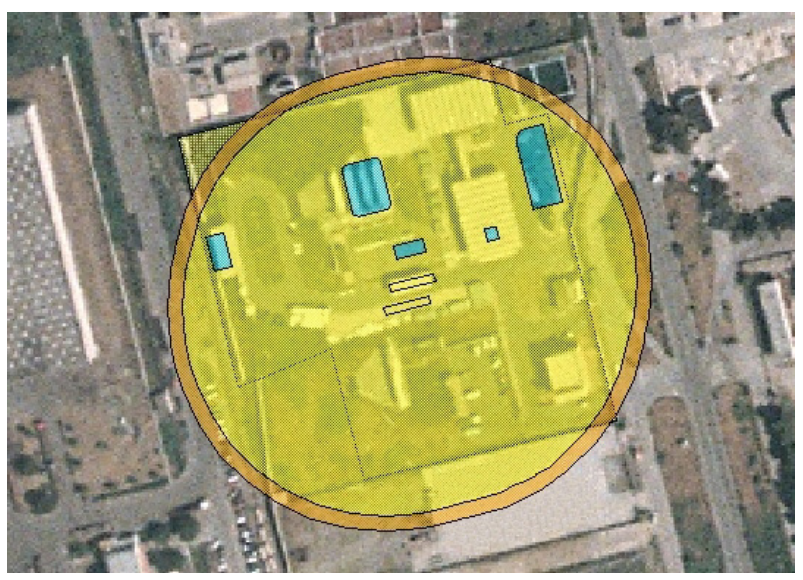

Figure 3: $\quad$ ARIA 334 - Flash-fire scenario representation.

Generally the flash-fire scenario is not considered as a possible cause of domino effect because of its short life, and the fact that it generally only damages those units that are easily attacked by fire. It does not cause any considerable radiation capable of damaging metallic equipment or structures. The only danger is the possible diffusion of the fire to other flammable materials that may eventually be present and exposed.

As already stated, the plant surroundings are of exclusive industrial destination, there are no vulnerable central points and the involved streets are not main streets. Consequently the represented events do not show any risks for the population and the environment.

\subsection{Application of ARIA 334 for a petrolchemical installation}

A great petrolchemical industry sited in a depressed area of Sicily, built ca.1950 in a disorder social context, has been also studied.

The industrial area is constituted from several complex industrial plants of different society. The extension of the industrial area is five million $\mathrm{m}^{2}$ and its borders are: North with state road and the railway, east with agricultural lands, south with the sea, west a small river. 
In the petrolchemical installation, approximately four and a half million tons of crude oil and methane are treated. Over the years an indiscriminate urbanization has meant that the petrolchemical area is now not far from the city centre, which could therefore be involved in some incident scenario.

Because of the position of the site, the products transfer is by road, railway or sea. The principal products of the petrolchemical installation are:

- oil

- petrolchemical products

- production energy and utilities

- warehouse, filling and commercialization of LPG, petrol and diesel.

The incidental event data and the damage scenario are extracted from the plant's safety report and from the emergency plan. The incidental events are chosen according to the worst consequences for the surrounding environment and considering the event frequencies.

As a toxic substance, ammonia is present in the plant: this is transported by railway in the industrial installation and it is discharged in 9 horizontal cylindrical tanks of a total capacity of $1000 \mathrm{t}$.

In the plant there are generally about $300 \mathrm{t}$ of ammonia and a tank is always left empty for emergencies. Then the ammonia is sent through the distribution pipes to the production units.

The initial event in the incidental scenario is the loss of liquid ammonia from the distribution line: the estimated frequency of the event is $7,83 \times 10^{-5} \mathrm{occ} . /$ years with an ammonia release speed of $2 \mathrm{~kg} / \mathrm{s}$.

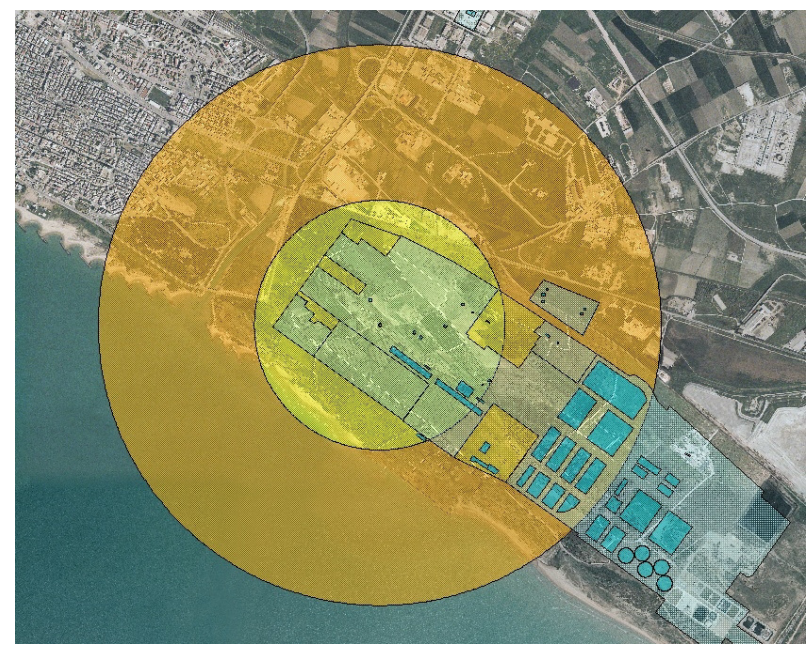

Figure 4: $\quad$ ARIA 334 - Toxic release scenario representation.

The conditions of atmospheric stabilities in which the incident event has been analyzed, are (F - $3 \mathrm{~m} / \mathrm{s}, \mathrm{D}-5 \mathrm{~m} / \mathrm{s})$. Different incident scenarios can occur: the most important considered event is radiation with a frequency of $3,9 \times 10^{-6}$ 
occ./year, a toxic release with a frequency of $7.2 \times 10^{-7}$ occ./year. The toxic release is associated with the IDLH to $1560 \mathrm{~m}$ and the LC50 to $690 \mathrm{~m}$. The graphical representation, under normal geographic and meteorological conditions (insufficient atmospheric precipitations in the course of the year), shows the toxic cloud near the town affecting some vulnerable centres such as schools, hospital and museums.

The second event involves the alchilation unit: in this process a mixture of olefins and acid solvent with a great percentage of isooctane is involved. The reaction is with excess isobutene in order to promote the formation of isoparaffine. The operating cycle is:

- reaction

- recover acid.

The reaction section has been subdivided in several circuits:

a) reaction and separation of acid;

b) refrigeration;

c) isobutene recovery;

d) propane recovery.

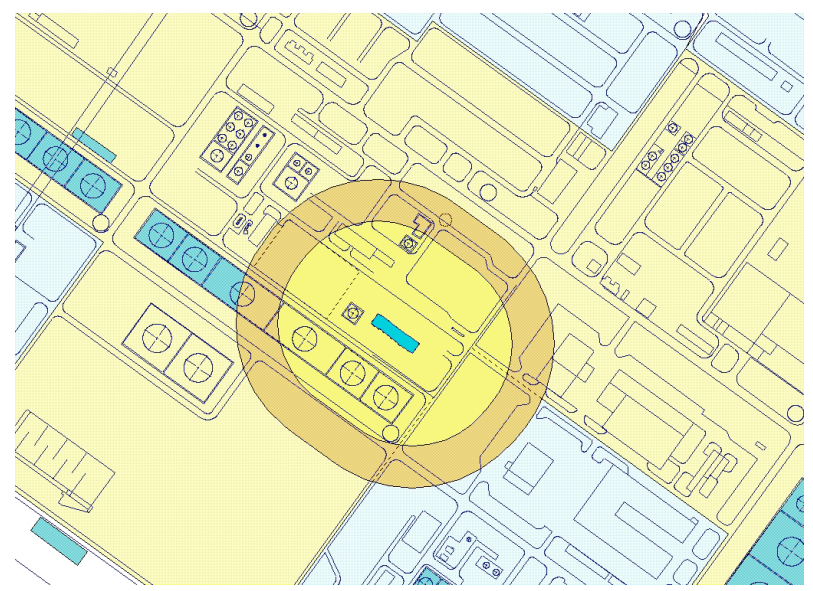

Figure 5: $\quad$ LPG release scenario representation.

Because of the complexity of the system, the number of considered accidents in this unit is remarkable.

The analysed events involve the piping of the technical units. These events, checked on the basis of the historical experience in petrolchemical systems, are random breakages not caused by operating process or by operative errors (corrosion or anomalous damage, assembly fault, anomalous tensions). In order to prevent these events, the company uses a rigorous program of maintenance and inspection.

Two events affect the processes of alchilation and the propane recover area, the third involves a generic section of piping in the same area. The releases have 
respectively frequencies $2,00 \times 10^{-4}, 1,51 \times 10^{-5}$ and $1,00 \times 10^{-5} \mathrm{occ}$./year. The release rates are $2,21,1,96$ and $4.77 \mathrm{~kg} / \mathrm{s}$. The scenario regards radiation, dispersion and UVCE. The software ARIA 334 shows the following representation:

Because of the release from the propane line, the generated radiation has a frequency of $2,0 \times 10^{-5} \mathrm{occ}$. $/$ year, $12,5 \mathrm{kw} / \mathrm{m}^{2}$ to a distance of $71 \mathrm{~m}, 7 \mathrm{kw} / \mathrm{m}^{2}$ to $84 \mathrm{~m}, 5 \mathrm{kw} / \mathrm{m}^{2}$ to $96 \mathrm{~m}$ and of $3 \mathrm{kw} / \mathrm{m}^{2}$ to $119 \mathrm{~m}$. The frequency dispersion is $1,6 \times 10^{-4} \mathrm{occ}$./years and a LFL to $91 \mathrm{~m}$ and $1 / 2 \mathrm{LFL}$ to $132 \mathrm{~m}$.

The UVCE frequency is $2,2 \times 10^{-5} \mathrm{occ}$./year and overpressure 0,3 bar to $9 \mathrm{~m}$, 0,14 bar to $41 \mathrm{~m}, 0,07$ bar to $54 \mathrm{~m}, 0,03$ bar to $87 \mathrm{~m}$.

In the case of the release from LPG hydroisomerization process line, the scenario is a radiation with a frequency of $1,5 \times 10^{-6} \mathrm{occ} . /$ year, $12,5 \mathrm{kw} / \mathrm{m}^{2}$ to $72 \mathrm{~m}$, of $7 \mathrm{kw} / \mathrm{m}^{2}$ to $85 \mathrm{~m}$, of $5 \mathrm{kw} / \mathrm{m}^{2}$ to $97 \mathrm{~m}$ and of $3 \mathrm{kw} / \mathrm{m}^{2}$ to $120 \mathrm{~m}$, dispersion with frequency $1,2 \times 10^{-5}$ occ./year, LFL to $108 \mathrm{~m}$ and $1 / 2$ LFL to 158 $\mathrm{m}$, UVCE with frequency of $1,7 \times 10^{-6} \mathrm{occ}$./year and overpressures of $0,3-0,14$,0,7-0,03 bar to $11-49-63-123 \mathrm{~m}$.

The last analyzed incident involves a generic pipe of the plant and has been represented as breaking of draining or cleaning piping. The frequency has been estimated in $1,00 \times 10^{-5}$ occ/years for $4,77 \mathrm{~kg} / \mathrm{s}$.

The scenario are radiation with frequency of $1 \times 10^{-6} \mathrm{occ} . / \mathrm{year}$, dispersion with frequency of $3,4 \times 10^{-6} \mathrm{occ}$./year with LFL to $133 \mathrm{~m}$ and $1 / 2 \mathrm{LFL}$ to $193 \mathrm{~m}$, toxic release with IDLH to $930 \mathrm{~m}$ and the LC50 to $350 \mathrm{~m}$.

Although domino effects may occur with serious consequences, and with an increase in the conditions of management of the emergency, none of these events have consequences that exceed the plant borders. The impossibility of representing the synergies between events that could simultaneously involve the same equipment unit, and represent domino effects are the main limits of the support system used for risk management. The development of software capable of analysing the risk as a result of domino effects, at least in an interactive way, is still at embryonic level and the software proposed at the moment are very simple prototypes, which are not suitable for the risk management associated with complex industrial areas.

\section{References}

[1] Contini S., Giardina G., Binda M., Bellezza F., (1998), Valutazione e gestione di rischi d'area, Proceedings VGR 1998, Pisa Italy.

[2] Spagli L., Ceccanti M., MossaVerre M. (1998), Valutazione del rischio d'area. Applicazione sperimentale del codice VARIAR alla zona di Piombino, Proceedings VGR 1998, Pisa Italy.

[3] Bartolozzi V., Castiglione L., Picciotto A., Galluzzo M. (2000), Qualitative models of equipment units and their use in automatic HAZOP analysis, Reliab Engng Syst Safety, Elsevier, 70: 49-57.

[4] EUROPEAN COMMISSION. STARS II: User Manual. Ispra (VR): JRC, 1997. 
122 Sustainable Development and Planning III

[5] Cocchiara M., Bartolozzi V., Picciotto A., Galluzzo M. (2001), Integration of interlock analysis with automated HAZOP analysis, Reliab Engng Syst Safety, Elsevier, 74:99-105.

[6] Carcassi M. N., Cecchella P., MossaVerre M., Poli U., (1998), Modelli perfezionati per lo studio speditivo del rischio d'area a forte concentrazione industriale. Un'applicazione all'area industriale di Piombino, Proceedings VGR 1998, Pisa Italy. 